\title{
Axonal Transport and Localization of B-50/GAP-43-like Immunoreactivity in Regenerating Sciatic and Facial Nerves of the Rat
}

\author{
W. Tetzlaff, ${ }^{1}$ H. Zwiers, $^{1}$ K. Lederis, ${ }^{2}$ L. Cassar, ${ }^{1}$ and $M$. A. Bisby ${ }^{1}$ \\ Departments of ${ }^{1}$ Medical Physiology and PParmacology and Therapeutics, University of Calgary, Calgary, \\ Alberta T2N 4N1, Canada
}

\begin{abstract}
Neurons that can regenerate their axons following axotomy increase their synthesis and axonal transport of a growthassociated protein, called GAP-43, which has been shown to be identical to the synaptic phosphoprotein B-50. The function of B-50/GAP-43 to the process of regeneration is unknown.

We used a polyclonal, affinity-purified antibody against B-50 to study the axonal transport and localization of B-50/ GAP-43-like immunoreactivity (B50LI) in the regenerating sciatic and facial nerves of adult rats. Quantitative data were obtained by densitometry of the B-50 band in immunoblots of nerve segments, which had been run on SDS-polyacrylamide gels. In the regenerating sciatic nerve, anterograde accumulation at a collection ligature was 3.0 times higher than retrograde accumulation. The mobile fraction of B5OLI was only 0.28 of total $B 50 \mathrm{LI}$ and traveled with a mean anterograde velocity of $5.3 \mathrm{~mm} / \mathrm{hr}$. B5OLI distribution in the newly regenerated portion of the nerve revealed maximal B50LI levels midway between the position of the crush and the fastest-growing axons.

Immunocytochemistry of this portion of the nerve demonstrated B5OLI to be associated with regenerating axons but also to a large extent with extra-axonal structures outlining the Schwann cell bands of Büngner. This zone of B50LIpositive Schwann cell bands was found to extend more distally in nerves in which regeneration had processed longer, e.g., up to $5 \mathrm{~mm}$ distal to the crush after $3 \mathrm{~d}$ and $8 \mathrm{~mm}$ after $4 \mathrm{~d}$. Further distal to this zone, many fine regenerating axonal profiles could be detected with B-50 antibody, but were neurofilament negative. These findings raise the possibility of an extra-axonal function of B-50/GAP-43, as this protein might be secreted from regenerating axons and might play a role in axon-Schwann cell interactions during axonal maturation.
\end{abstract}

\footnotetext{
Received July 7, 1988; accepted Sept. 1, 1988.

This work was supported by Medical Research Council of Canada grants MT5198 (to M.A.B.) and MT3911 (to K.L.). H.Z. is a scholar and W.T. is a fellow of the Alberta Heritage Foundation for Medical Research. We would like to express our gratitude to Jodi Houston and David Ko for preparing the B-50 antibodies, to Dr. Phil Coggins for reverse phase HPLC of B-50, and to Ilona Berbeker for excellent technical assistance.

Correspondence should be addressed to Dr. Wolfram Tetzlaff, Department of Medical Physiology, University of Calgary, 3330 Hospital Drive N.W., Calgary, Alberta T2N 4N1, Canada.

Copyright (C) 1989 Society for Neuroscience $0270-6474 / 89 / 041303-11 \$ 02.00 / 0$
}

Axotomy of peripheral nerves is followed by changes in neuronal protein synthesis that are thought to be necessary to sustain subsequent axonal regeneration. Since all proteins required for axonal growth have to be conveyed by axonal transport from the cell body to the growing axon, the study of axonal transport in regenerating nerve has revealed changes in components of both slow and fast transport. Thus, there are decreases in the synthesis and transport of neurofilament proteins and increases in tubulin and actin transport relative to normal axons (Hoffman et al., 1985, 1987; Tetzlaff et al., 1988). Among the large number of unidentified proteins of fast transport, the most dramatic increase following axotomy is exhibited by a protein designated growth-associated protein (GAP) 43 (Skene, 1984), whose transport increases $50-100$-fold. Interestingly, there is a correlation between the increased synthesis and transport of GAP- 43 following axotomy and the ability of axons to regenerate. All peripheral mammalian axons show increased GAP-43 transport following axotomy, but axons of the adult optic nerve and corticospinal tract do not (Skene and Willard, 1981b; Kalil and Skene, 1986; Reh et al., 1987). However, optic nerve axons in the goldfish (Benowitz and Lewis, 1983) and toad (Skene and Willard, 1981a), which can regenerate, show increased transport of a GAP-43 analog. This correlation suggests that increased GAP-43 synthesis is necessary for regeneration to occur and implies that this protein plays a vital role in regeneration.

Recently, several laboratories have reported that GAP- 43 is identical to proteins designated pp46, a component of growth cones (Meiri et al., 1986; Skene et al., 1986); F1, a phosphoprotein implicated in synaptic plasticity (Lovinger et al., 1985); P57, a neural-specific calmodulin-binding protein (Cimler et al., 1987); and B-50, a synaptic phosphoprotein that is a major substrate for protein kinase $C$ and modulates the activity of the phosphatidylinositol second-messenger pathway (Gispen, 1986; Zwiers et al., 1987). Information about the biochemistry of B-50 may permit us to elucidate the functions of GAP-43 in axonal regeneration. Moreover, the availability of specific polyclonal antibodies against B-50 (Oestreicher et al., 1983) has allowed us to examine the localization of this protein, hereafter designated $\mathrm{B}-50$, within regenerating peripheral nerves. As expected, we found that B-50-like immunoreactivity (B50LI) was rapidly transported in both anterograde and retrograde directions and was localized within newly regenerated axons. Totally unexpected was the finding that in the region of the regenerating nerve containing the highest levels of B50LI, proximal to the position of the fastest-growing axons, B50LI was associated with 
Schwann cell profiles of the bands of Büngner. Because preliminary experiments disclosed no evidence of B-50 synthesis by isolated nerve segments, we concluded that B-50 must be secreted from regenerating axons in order to reach the Schwann cell membranes or adjacent basal lamina. This finding prompts a new range of speculations about the function of B-50 in regeneration.

\section{Materials and Methods}

Animals. Adult male Sprague-Dawley rats weighing 250 to $320 \mathrm{gm}$ were kept at a 14-hr-light/10-hr-dark cycle and fed with standard diet and water ad libitum.

Axonal transport of $B-50$. Classical ligature techniques (Bisby, 1982) were used to measure the accumulation of B50LI undergoing transport in anterograde and retrograde directions. Seven days following a distal crush made on the sciatic nerve at the level of the knee, to induce B-50 synthesis, 2 collection ligatures were placed approximately $9 \mathrm{~mm}$ apart on the proximal part of the sciatic nerve, with the most distal ligature at least $10 \mathrm{~mm}$ proximal to the original crush site. Six hours later the rats were killed by anesthetic overdose, and the nerves were removed, mounted on cardboard strips, and frozen on dry ice. Subsequently, the nerves were cut into segments as shown in Figure $1 A$; each segment was first pulverized with a steel punch at dry ice temperature and then homogenized with a Teflon pestle in an Eppendorf centrifuge tube containing $70 \mu 11 \%$ SDS in distilled water $\left(4^{\circ} \mathrm{C}\right)$.

Isolation of B-50 immunoglobulins. Antibodies directed to B-50 were raised in New Zealand rabbits by 4 monthly injections (intradermally in the neck), each of about $1 \mathrm{mg}$, of B-50 in Freund's Complete Adjuvant. The injected B-50 was purified according to Zwiers et al. (1985) from rat brain tissue. The degree of purity of the injected preparations obtained (after flatbed isoelectric focusing; called IEF-B-50) was $>95 \%$, as assessed by SDS-PAGE.

Affinity-purified B-50 IgGs were isolated by incubating the antiserum with a B-50 affinity column. The B-50 (1 mg) used to prepare this column was obtained by electroelution of IEF purified B-50 out of SDS-slab gels. In this way trace amounts of contaminants differing in MW from B-50 were removed. For details of the procedure, see Oestreicher et al. (1983). From $1 \mathrm{ml}$ of serum, approximately $30 \mu \mathrm{g}$ of specific B-50 IgGs were obtained, which were then dissolved in $150 \mu$ l PBS.

Immunostaining of B-50 on Western blots. Aliquots of the homogenates of 3-mm sections of sciatic nerve were separated on SDS-containing polyacrylamide slab gels ( $11 \%$ acrylamide) as described before (Zwiers et al., 1985). After electrophoresis the gel was soaked for 20 min in "transblot buffer" (25 mm Tris, $192 \mathrm{~mm}$ glycine, $20 \%$ methanol, $0.1 \%$ SDS, pH 8.3). Transfer of proteins to nitrocellulose (Biorad, Richmond, CA) was performed by electrophoresis at $250 \mathrm{~mA}$ for $18 \mathrm{hr}$ at $4^{\circ} \mathrm{C}$. The blot was air dried, blocked for $30 \mathrm{~min}$ at $25 \mathrm{~mm}$ phosphatebuffered $0.8 \%$ saline, pH 7.4, with 3\% BSA, and incubated with B-50 IgGs (about $5 \mu \mathrm{g} / 20 \mathrm{ml}$ of blocking buffer) for $18 \mathrm{hr}$ at $22^{\circ} \mathrm{C}$. Excess antibody was removed by 3 washes in PBS followed by 3 washes with $20 \mathrm{~mm}$ Tris- $\mathrm{HCl}(\mathrm{pH} \mathrm{7.5)}, 250 \mathrm{mM} \mathrm{NaCl}$, and $0.05 \%$ Tween 20 (buffer A) and subsequently was incubated for $2 \mathrm{hr}$ with the second antibody (anti-rabbit IgG-alkaline phosphatase conjugated, Sigma, St. Louis; diluted 1:1000 with buffer A). Unbound antibodies were removed by 3 subsequent wash steps (buffer A), and finally the blot was incubated with 5-bromo-4-chloro-3-indolyl phosphate (BCIP; $0.5 \mathrm{mg} / \mathrm{ml}$, dissolved in $300 \mu \mathrm{l}$ dimethylsulfoxide and then diluted to $20 \mathrm{ml}$ with 0.5 $\mathrm{M}$ Tris, $\mathrm{pH}$ 8.8). Intense blue stained bands revealed the position of B-50 within $30 \mathrm{~min}$. Other, faintly stained, bands were also observed. These persisted when the blots were incubated with B-50 IgGs preabsorbed with excess B-50, which eliminated the B-50 band.

Determination of relative amounts of B50LI in nerve samples. Amounts of total protein in the homogenates of nerve segments were determined by the method of Lowry et al. (1951). Aliquots of $3 \mu \mathrm{l}$ were assayed in triplicate in a volume of $440 \mu$ l. Under these conditions SDS (1\%) present in the samples did not interfere with the assay. Amounts of reference B-50 and of B-50 IgGs were determined by comparison of Fast green staining on SDS gels with known amounts of BSA. To provide a semiquantitative assay for B50LI in each nerve segment, calibration curves were constructed using B-50 standards (Fig. 1B).

Calculations for axonal transport were the same as those used previously for determinations of the axonal transport of substance-P-like immunoreactivity (Bisby and Keen, 1985). The proportion of B50LI that was mobilc over the 6-hr collection period was determined by measuring the depletion of the center segment of the isolated nerve relative to the mean $\mathrm{B} 50 \mathrm{LI}$ content of the isolated segment, on the assumption that B50LI is neither synthesized nor lost during the collection period. Thus,

$$
\text { mobile fraction }(M F)=1-\frac{C / L c}{(B+C+D) / L_{b+c+d}}
$$

where $\mathrm{B}, \mathrm{C}, \mathrm{D}=$ the $\mathrm{B} 50 \mathrm{LI}$ of the respective segments (Fig. $1 A$ ) and $\mathrm{Lx}$ $=$ the length of a segment $\mathrm{x}$.

Accumulation of B-50 at the collection ligatures was defined as

$$
\text { Anterograde accumulation }(A A)=\frac{A}{L a}-\frac{(B+C+D)}{L_{b+c+d}}
$$

and

$$
\text { Retrograde accumulation }(\mathrm{RA})=\frac{\mathrm{E}}{\mathrm{Le}}-\frac{(\mathrm{B}+\mathrm{C}+\mathrm{D})}{\mathrm{L}_{\mathrm{b}+\mathrm{c}+\mathrm{d}}}
$$

and the ratio between anterograde and retrograde transport was simply AA/RA. Velocity of transport was calculated by estimating the length of nerve whose mobile B-50 moved to the accumulation segment during the 6-hr collection period:

$$
\text { Velocity }=\mathrm{AA} /\left(\frac{\mathrm{B}+\mathrm{C}+\mathrm{D}}{\mathrm{L}_{\mathrm{b}+\mathrm{c}+\mathrm{d}}}\right) \times \frac{\mathrm{MF}}{6} \mathrm{~mm} / \mathrm{hr} \text {. }
$$

To determine the B50LI of the regenerating nerve, the right sciatic nerve was crushed proximally, at the fused gemelli and obturator tendon, and $5 \mathrm{~d}$ later the rats were re-anesthetized. The position of the fastestgrowing axons was determined by the pinch reflex test (Gutmann et al. 1942). The animals were then killed, and both sciatic nerves and L5 dorsal root ganglia (DRG) were removed and processed as described above.

Immunocytochemistry. The sciatic or facial nerves were crushed twice for $30 \mathrm{sec}$ with a pair of Dumont forceps and allowed to regenerate for $3,4,5$, and $7 \mathrm{~d}$. To visualize the axonally transported $\mathrm{B}-50$ fraction in the sciatic nerve, collection ligatures were placed around a sciatic nerve that had been regenerating for $7 \mathrm{~d}$. These ligatures were placed $10 \mathrm{~mm}$ proximal to the original crush and were left for $7 \mathrm{hr}$; thereafter, the nerves were excised, mounted, and frozen. Another group of nerves was studied $7 \mathrm{~d}$ after resection of a $10-\mathrm{mm}$ nerve segment that impeded regeneration and resulted in a neuroma formation.

The fresh facial or sciatic nerves were cut into $10-\mathrm{mm}$ segments, mounted side-by-side in Tissue-Tek (O.C.T.-compound, Miles Scientific, Naperville, IL), and frozen on dry ice. In such a way a distance of 30 to $40 \mathrm{~mm}$ could be cut longitudinally on a cryostat at $20 \mu \mathrm{m}$ thickness. The sections were thaw-mounted on gelatine-chromalumn subbed slides and stored at $-70^{\circ} \mathrm{C}$. Prior to immunostaining, these were fixed for 20 $\mathrm{min}$ in $4 \%$ paraformaldehyde which was either Tris- $\mathrm{IICl}$ or phosphate buffered ( $\mathrm{pH} \mathrm{7.4).} \mathrm{After} \mathrm{several} \mathrm{rinses} \mathrm{in} \mathrm{Tris-HCl} \mathrm{or} \mathrm{PBS} \mathrm{(pH} \mathrm{7.4),} \mathrm{the}$ sections were incubated in $1 \% \mathrm{BSA}$ and $0.02 \%$ Triton X-100 in buffered saline for $1 \mathrm{hr}$. In some experiments, SDS $(0.01 \%)$ was used instead of Triton X-100. Triton X-100 pretreatment allowed sufficient penetration of the antibodies and gave better tissue preservation than SDS pretreatment, and was therefore used in the micrographs shown. After this pretreatment the sections were incubated with affinity-purified B-50 antibodies diluted $1: 100$ to $1: 200$ in PBS for $14-16 \mathrm{hr}$ at room temperature. Both buffer systems gave the same results with respect to the $\mathrm{B}-50$ immunostaining. After several rinses with PBS, the sections were incubated with goat IgG $(1.0 \%$, w/vol in PBS) for $30 \mathrm{~min}$, followed by staining with a rhodamine-labeled goat-anti-rabbit-IgG antibody (Cappel-Cooper Biomedical, Malvern, NY) for $1 \mathrm{hr}$, and briefly rinsed in PBS. In order to visualize axonal structures, the sections were incubated with monoclonal antibody to neurofilament $160 \mathrm{kDa}$ protein (Boehringer-Mannheim, FRG) in a dilution of 1:20-1:50 in PBS. Bound antibodies were visualized with a fluorescein-labeled goat-anti-mouseIgG antibody (Cappel). As controls, sections were incubated either with rabbit preimmune serum diluted 1:30 and $1: 200$ or with $B-50$ antibodies preabsorbed to highly purified B-50 obtained by reverse-phase high performance liquid chromatography (HPLC) as detailed in McMaster et al. (1988). Controls with only the secondary antibodies gave no staining, and there was no evidence of a cross-reactivity of the 2 secondary antibodies used. 

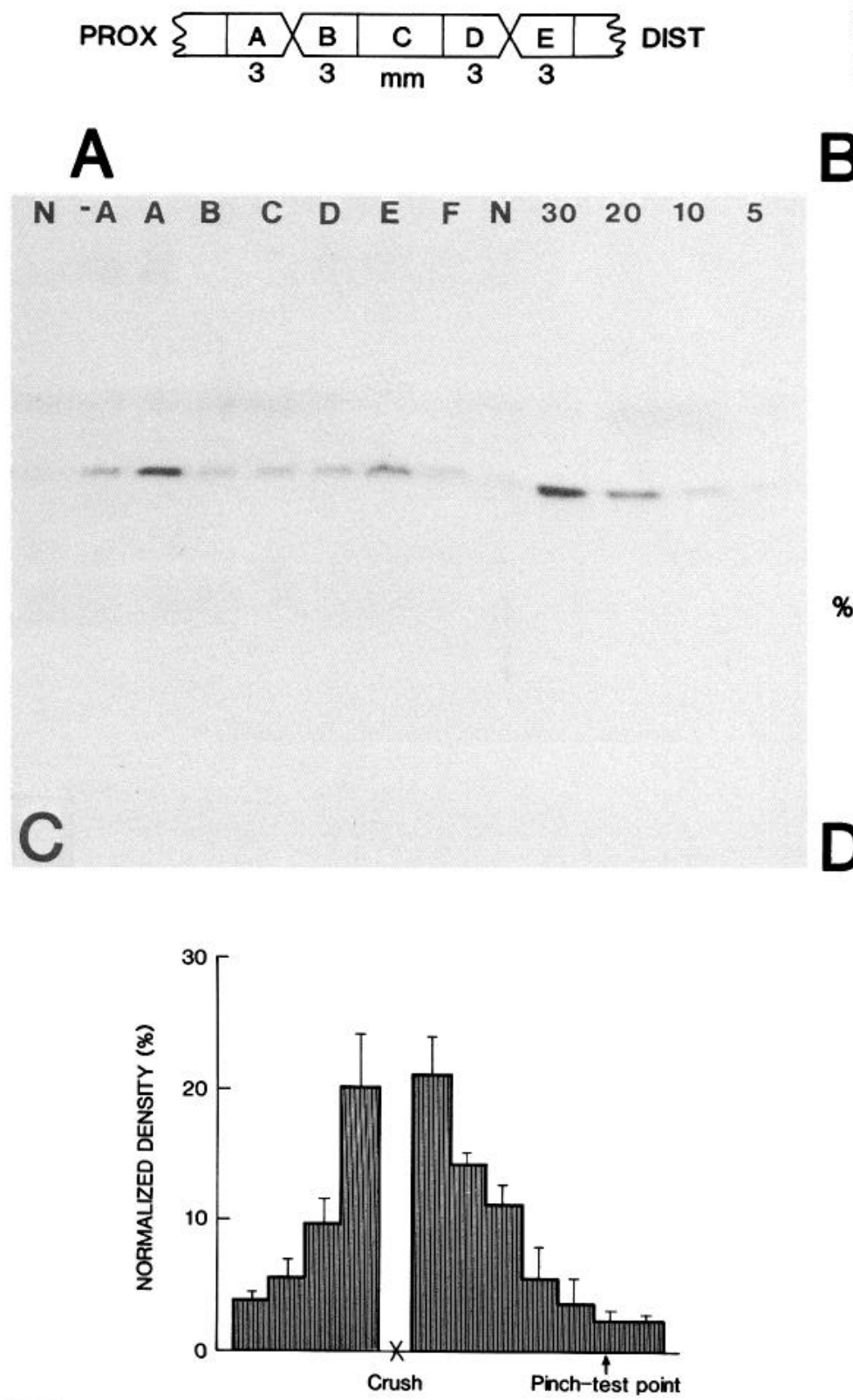
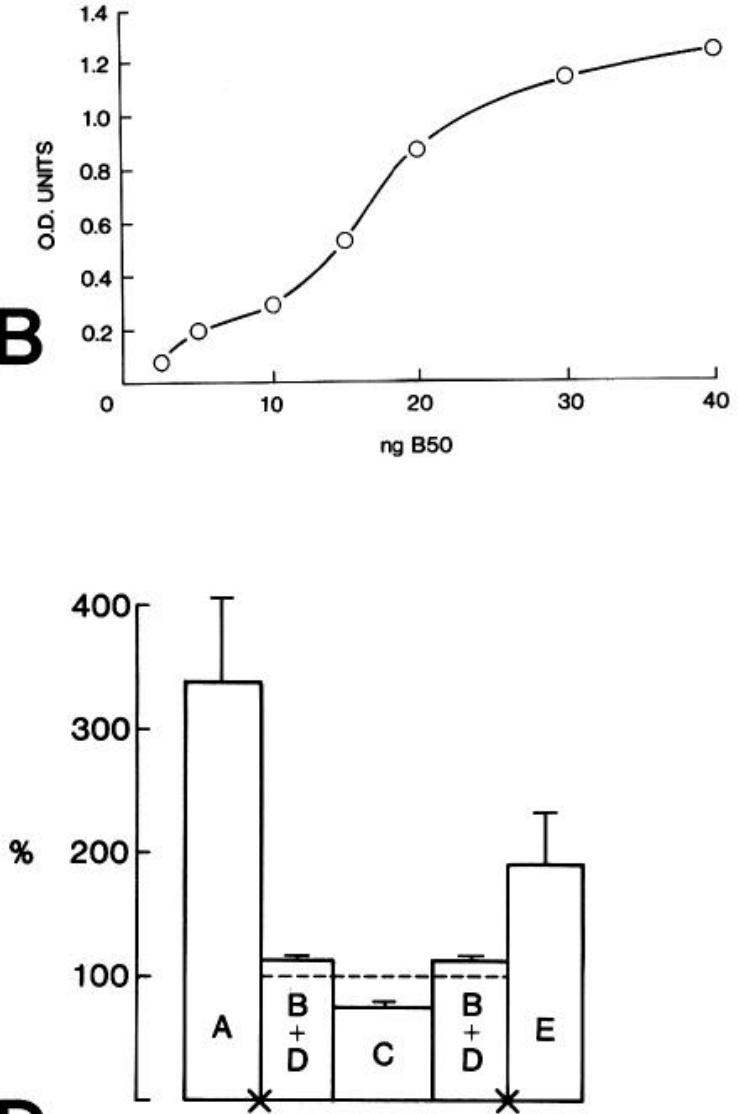
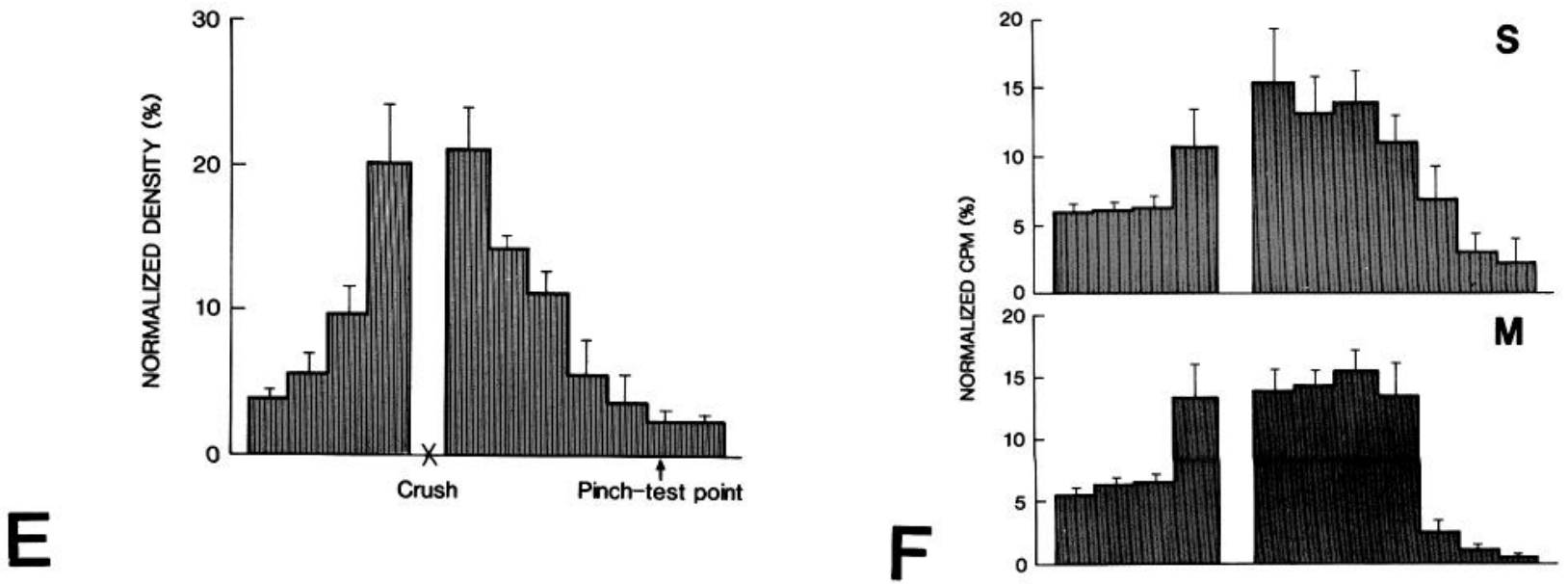

Figure 1. A, Diagram of sciatic nerve segments taken for axonal transport determinations. The length of segment $C$ was variable, but usually 3 mm. $B$, Calibration curve for B50 standards on an immunoblot. $C$, Representative immunoblot: $N, 3-\mathrm{mm}$ segment of normal nerve; $-A, 3$-mm segment proximal to segment $A ; A-E$, Segments as shown in $A ; F, 3-\mathrm{mm}$ segment distal to $E$. Numbers indicate ng of purified B50 added to each standard lane. Nerve segment B50LI falls within the range of standards on this gel. $D$, Distribution of B50LI in 7-d regenerating nerve 6 hr after application of collection crushes $(A)$ to the nerve, approximately $10 \mathrm{~mm}$ proximal to the original crush injury. Values are normalized to the mean immunoreactivity of the isolated segment $(B+C+D)$ for each nerve. Segments $B$ and $D$ were pooled. Means \pm SEM are shown; $n=8$, except in segment $E$ where $n=6 . E$, Distribution of B50LI in 5-d regenerating nerve. Each bar represents a 3-mm nerve segment, proximal to left. $X$, Site of original crush injury; arrow, mean position of the fastest-growing axons, as determined by pinch-reflex test. Values are normalized by expressing total B50LI in the length of nerve as $100 \%$. Means \pm SEM are shown; $n=7 . F$, Distribution of axonally transported [3H]protein in 5 -day regenerating rat sciatic nerve after injection of $\mathrm{L}-[3 \mathrm{H}]$ leucine into $\mathrm{L} 5$ dorsal root ganglion $(S)$ or lumbosacral spinal cord $(M)$ to label sensory and motor axons, respectively. Data from Redshaw and Bisby, $1987(S)$, and Bisby, $1985(M)$. Normalized data, as in $E . n=4(S)$; n $=5(M)$. 


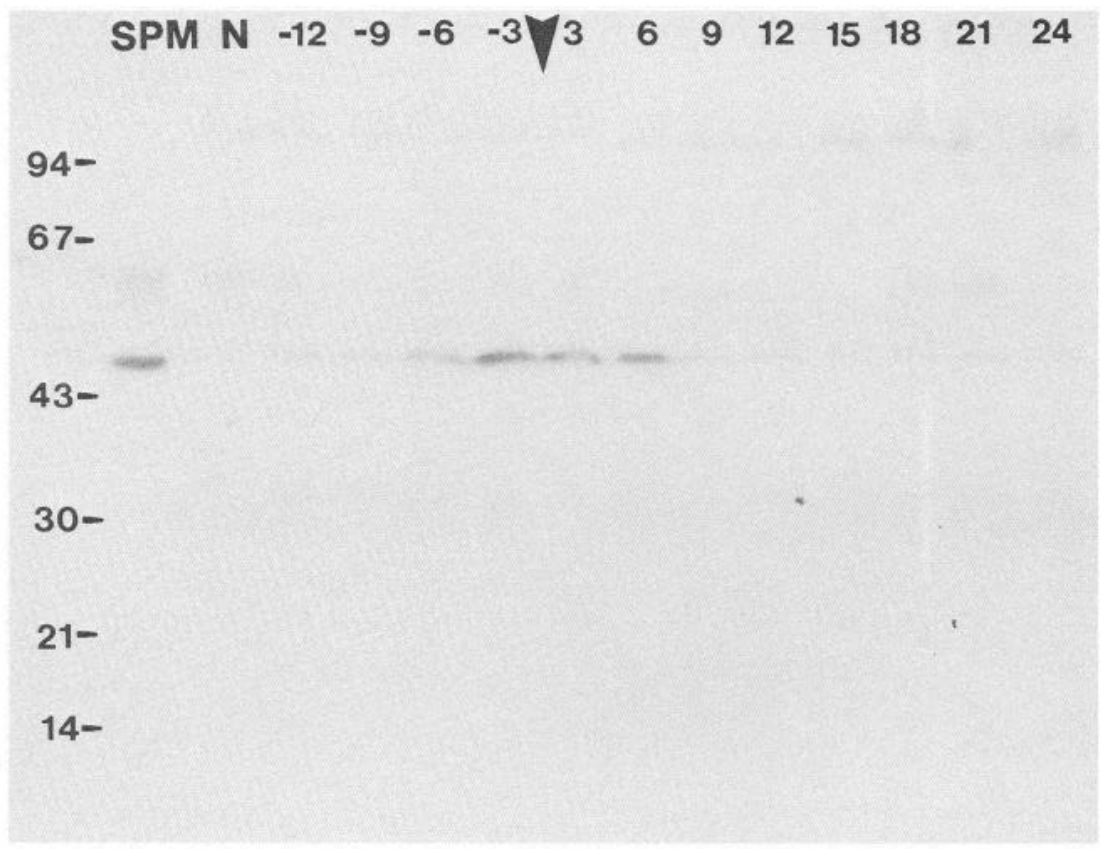

Figure 2. Immunoblot of 5-d regenerating sciatic nerve segments. Each lane contains a $3-\mathrm{mm}$ segment of nerve, proximal to the left. Numbers refer to the position of the border of the segment farthest from the crush site in $\mathrm{mm}$. Crush site indicated by arrow. Vertical scale shows position of molecular weight markers, in kilodaltons. $N$, Contralateral normal nerve; $S P M$, Synaptosomal plasma membranes, a rich source of B-50.

Electron microscopy. For EM immunocytochemistry, 8 rats whose sciatic nerves had been crushed $5 \mathrm{~d}$ previously were perfused with phosphate-buffered paraformaldehyde $(2 \%)$ plus L-lysine $(0.1 \mathrm{M})$ and sodium periodate $(0.05 \mathrm{M})$ (McLean and Nakane, 1974). Three-millimeter segments of the sciatic nerves were excised and postfixed overnight in the same fixative at $4^{\circ} \mathrm{C}$. They were cryoprotected in $8 \%, 14 \%$, and $20 \%$ dimethylsulfoxide (DMSO) before being shock-frozen in acetone cooled on dry ice. In some samples the cryoprotection/permeabilization with DMSO was substituted with sucrose (10-30\%) with less intense but qualitatively similar results. Cryostat sections were cut at $20 \mu \mathrm{m}$ and thawed in PBS containing 2\% DMSO and 1\% BSA. They were subsequently incubated overnight in the primary anti-B- 50 antibody, which had been affinity purified (see above) and preabsorbed to normal rat serum. After 1-3 d of incubation, the sections were rinsed in PBS and blocked in $1 \%$ goat-IgG (Sigma) in PBS with $2 \%$ DMSO plus $1 \%$ BSA and then incubated for at least $12 \mathrm{hr}$ in goat anti-rabbit-IgGs. After several rinses in PBS, the endogeneous peroxidase activity was blocked in hydrogen peroxide $(0.02 \%)$ for $1 \mathrm{hr}$. This was followed by several rinses in PBS and subsequent incubation with an anti-peroxidase-complex that was raised in rabbit (Sigma). Diaminobenzidine $0.5 \mathrm{mg} / \mathrm{ml}$ (Sigma) was used as a substrate for peroxidase reaction, followed by glutaraldehyde and osmium-tetroxide postfixation. Embedding in Epon and light staining with lead citrate/uranyl acetate were performed according to standard protocols. Controls incubated with pre-immune serum of the same rabbit were essentially blank. Preabsorption of the antibodies with an excess $(20 \times)$ or purified B-50 still showed some residual staining that was similar in its distribution.

\section{Results}

\section{Axonal transport}

Accumulation of B50LI both proximal to and distal to the collection ligatures, relative to the average B50LI within the isolated segment, showed that it was transported in both anterograde and retrograde directions (Fig. 1, $C, D$ ). Anterograde accumulation was $3.0 \pm 0.47$ (mean $\pm \mathrm{SEM}, n=6$ ) times greater than retrograde accumulation. The mobile fraction was $0.28 \pm$ $0.05(n=8)$ of total B50LI (1.0), and the calculated mean anterograde velocity was $5.3 \pm 0.72 \mathrm{~mm} / \mathrm{hr}(n=8)$.

\section{$B 50 L I$ distribution in regenerating nerve}

B50LI was greater in L5 DRG on the nerve-injured side: for 4 animals the average increase was a factor of 5.3. Figure $1 E$ shows the average distribution of B50LI in regenerating nerve, and Figure 2 shows a typical blot. Proximal to the crush site, B50LI was $2.3 \pm 0.58(n=7)$ times greater than in the contralateral uninjured nerve. An accumulation occurred proximal to the site of injury, presumably representing B50LI in abortive spouts. The highest levels of B50LI were found in the newly regenerated portion of the nerve, immediately distal to the crush site. This distribution differs from that of total $3 \mathrm{H}$-labeled fast axonally transported proteins (Fig. $1 F$ ). B50LI levels distal to the fastestgrowing axons were low but detectable: this may represent B50LI intrinsic to cells of the nerve sheath or B50LI from nerve not yet destroyed during Wallerian degeneration.

\section{Immunocytochemical localization of B50LI}

Immunocytochemistry of single $7 \mathrm{hr}$-collection ligatures of the regenerating (proximal to the primary crush) sciatic nerve also revealed more $\mathrm{B} 50 \mathrm{LI}$ proximal to a collection ligature (Fig. $3 \mathrm{C}$ ) than distal to it (Fig. 3D). As expected, there was far less B50LI in the nonregenerating contralateral nerve of the same animal, but in this normal nerve there was no obvious quantitative difference between distal and proximal accumulations (Fig. 3, $A, B)$. B50LI accumulating at the ligature appeared to be associated with axonal profiles but was also seen extra-axonally in the damaged tissue adjacent to the ligature. The axonal damming of B50LI is shown in more detail in Figure $3 F$, taken from the regenerating nerve $0.3-0.5 \mathrm{~mm}$ proximal to the ligature. The neurofilament immunoreactivity (NFI) is displayed in parallel (Fig. $3 E$ ). There was consistently more B50LI in regenerating nerves than in nonregenerating contralateral control nerves. This was most obvious when comparing a transected (and $1 \mathrm{~cm}$ resected) sciatic nerve $3 \mathrm{~mm}$ proximal to the cut (Fig. $3 H$ ) to the contralateral control nerve $7 \mathrm{~d}$ after lesion (Fig. $3 G$ ). There was no detectable B50LI in the distal nerve stump at $7 \mathrm{~d}$ after transection when axonal regeneration was hampered by resection of a 1-cm-long nerve segment (not shown). The cellular localization of the B50LI $3 \mathrm{~mm}$ proximal to the sciatic nerve crush is visible at higher magnifications in Figure $4, A-D$. Cross sec- 

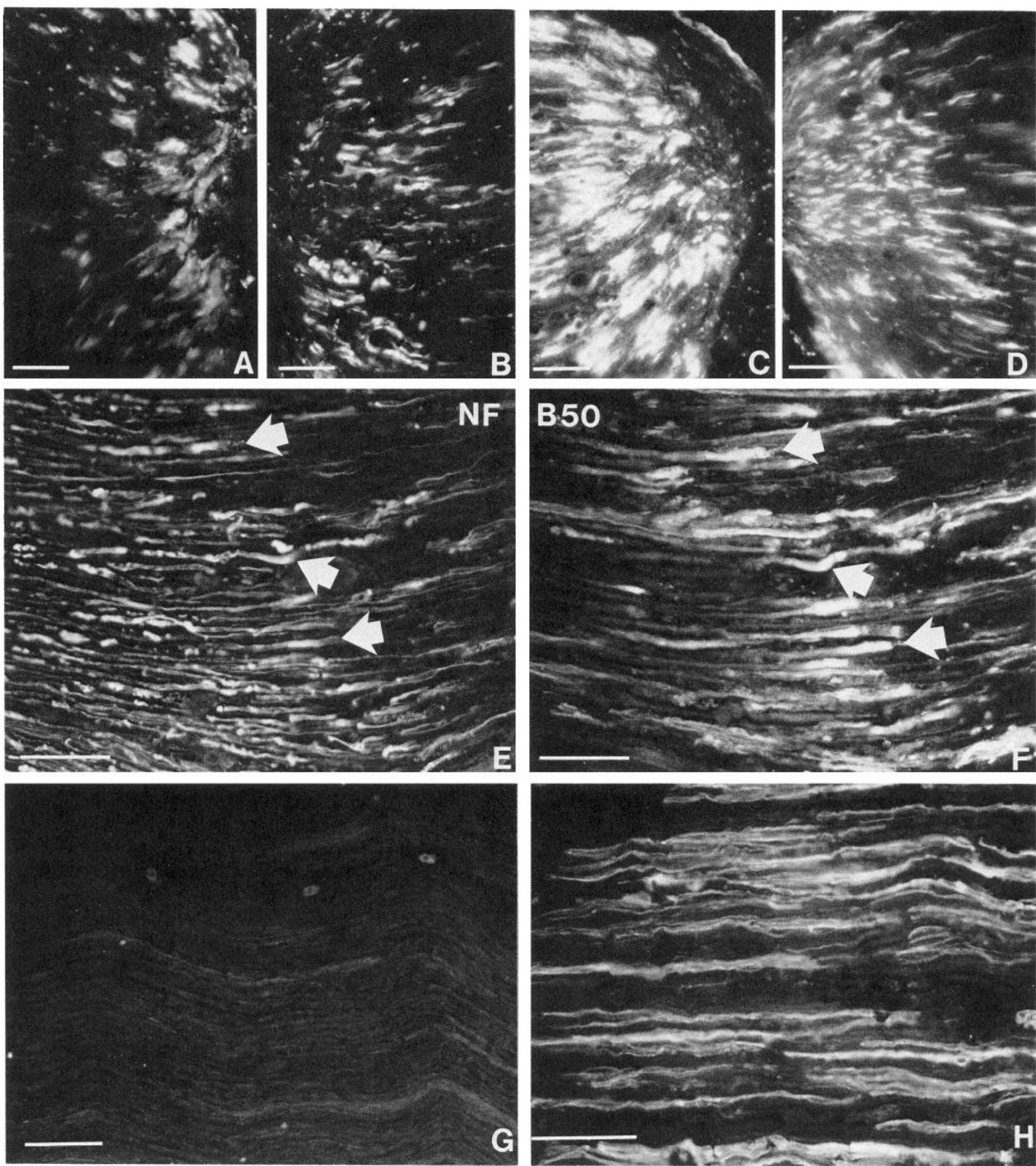

Figure 3. B50LI accumulating proximal $(A, C)$ and distal $(B, D)$ to a collection ligature placed for $6 \mathrm{hr}$ on a 7 -d regenerating sciatic nerve proximal to the original crush $(C, D)$ and on the contralateral control nerve $(A, B)$. Note the higher B50LI in the regenerating sciatic nerve in $C$ and $D ; A-$ $D$ were taken and printed at identical photographic exposures. More B50LI accumulated proximal $(C)$ than distal $(D)$ to the crush. $E$ and $F$ were taken $0.5 \mathrm{~mm}$ proximal to $C$. Double stain for B50LI $(F)$ and neurofilament polypeptide $150(E)$. B50LI accumulates in axonal profiles that also show typical axonal damming of NFI (arrows). $G, H$, B50LI in a non-operated control nerve $(G)$ and in a transected sciatic nerve 3 mm proximal to nerve transection at $7 \mathrm{~d}$ after operation $(H)$. Scale bars, $100 \mu \mathrm{m}$. 

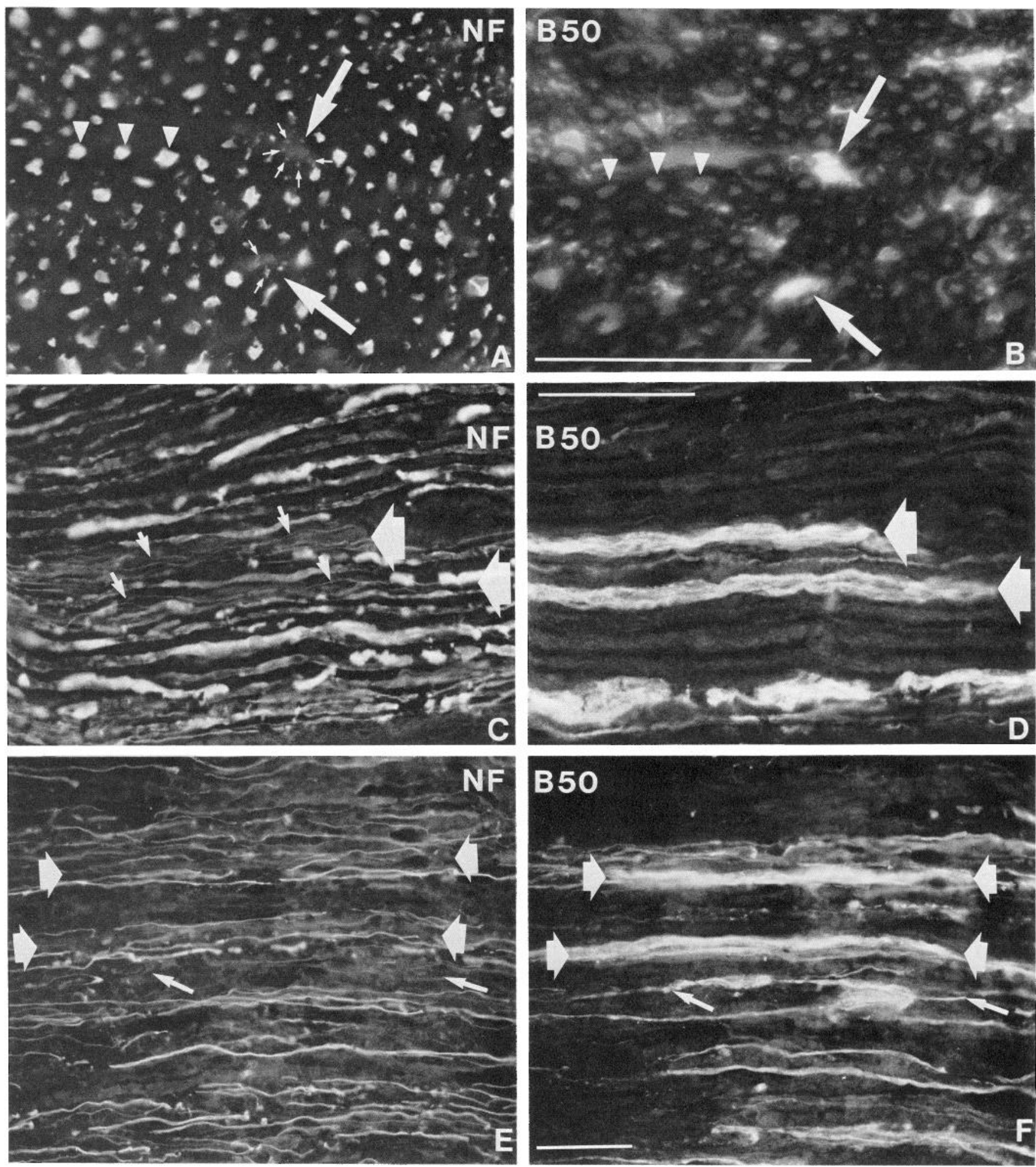

Figure 4. Regenerating rat sciatic nerve. Double stain for NFI $(A, C, E)$ and B50LI $(B, D, F) . A, B$, Cross section of a regenerating nerve $3 \mathrm{~d}$ after nerve crush at $3 \mathrm{~mm}$ proximal to the crush site. Note B50LI in the myelinated axons (arrowheads) but also between the myelinated nerve fibers (large arrows), where it is associated with unmyelinated nerve fibers with small axons (small arrows). $C, D$, Association of B50LI $(D)$ with Schwann cells and unmyelinated nerve fibers $(C, D$, large arrows), $7 \mathrm{~d}$ after crush, $8 \mathrm{~mm}$ proximal to crush; small arrows in $(C)$ are unmyelinated axons. $E$, $F$, Regenerating sciatic nerve $8 \mathrm{~mm}$ distal to the crush site at $7 \mathrm{~d}$ post-lesion. Note B50LI $(F)$ in regenerating axons (small arrows) and in Schwann cell bands of Büngner (large arrows). Many axons display NFI but not B50LI; conversely, many B50LI-positive axons do not stain with the neurofilament antibody (small arrows). Scale bars, $100 \mu \mathrm{m}$. 
tions revealed myelinated axonal profiles moderately stained with anti-B-50 (Fig. 4B, arrowheads). However, the strongest immunostaining was located between these myelinated nerve fibers (Fig. 4B, large arrows), where it was associated with nonmyelinated Remak fibers that have several small neurofilamentpositive axons (Fig. $4 A$, small arrows). This strong association of B50LI with the Schwann cells of Remak fibers (Fig. $4 C$, small arrows) was also visible in longitudinal sections (Fig. $4, C, D$ ). In unoperated control nerves this feature was also visible; however, the immunostaining was far less pronounced (see Fig. $3 G$ ).

Distal to the crush site, B50LI was associated with regenerating axons (Fig. $4 F$, small arrows) and Schwann cell bands (Fig. $4 F$, large arrows; $7 \mathrm{~d}$ after crush, $8 \mathrm{~mm}$ distal to the crush). These Schwann cell bands of Büngner, which stained positively for B-50, were usually associated with very small neurofilamentpositive axons (Fig. $4 E$ ). The majority of the neurofilamentpositive regenerating axons did not display intra-axonal B50LI (Fig. 4, E, F), and, conversely, many axonal profiles were positive for B-50 but could not be seen with neurofilament staining (Fig. $4 F$, small arrows). Thus, the highest concentration of B50LI, which was found near the crush site (Fig. 1E), was associated with Schwann cell profiles rather than axons. This zone of Schwann cell-associated B50LI moved down the nerve as regeneration of the axons proceeded: its distal boundary was 3$4 \mathrm{~mm}$ distal to the crush at day $3,9-10 \mathrm{~mm}$ at day 5 , and 14 $15 \mathrm{~mm}$ at day 7 . However, further distal to this zone many small-diameter axonal profiles were visible with B50LI staining but were NFI negative. Regeneration of these fastest growing axons, as revealed by B50LI, extended $11 \mathrm{~mm}$ distal to the crush on day 3 and 17-20 $\mathrm{mm}$ on day 5, giving a regeneration rate of $3-4.5 \mathrm{~mm} / \mathrm{day}$, which was in agreement with pinch-reflex data (Bisby, 1978).

The sciatic nerve contains a variety of different nerve-fiber types that may differ in their time course of regeneration and/ or in their B-50 content. In order to obtain a less complicated picture of the sequence of events, we also examined the regenerating facial nerve, which consists largely of motoneuron axons. The regenerating facial nerve was studied 3,4 , and $5 \mathrm{~d}$ after crush. Cross-sectioned areas of the regenerating nerve proximal to the crush revealed B50LI in the axonal profiles that also stained with neurofilament antibodies (Fig. 5, $A, B$ ). As there are virtually no unmyelinated axons in the facial nerve, no unmyelinated fibers were stained with B50LI. At the crush site and several millimeters distal to the crush, Schwann cell bands of Büngner were B50LI positive (Fig. 5, D, F,H). This zone of B50LI in Schwann cell bands extended about 4-5 $\mathrm{mm}$ distal to the crush site by $3 \mathrm{~d}$ (Fig. $5 H$ ), and 7-8 $\mathrm{mm}$ distal to the crush on day 4 (Fig. $5 D$ ). The B50LI-positive Schwann cell bands were often associated with small regenerating axons, which were neurofilament-positive (Fig. $5 C$, arrows). When they were associated with a B-50-positive Schwann cell band, it was in most cases not possible to detect these small axons with B-50 immunostaining. B50LI within these bands could not be localized unequivocally; however, it appeared to spare the myelin debris that usually fills these cells (Fig. $5 F$, arrowheads) and to be associated with the outer Schwann cell profiles (Fig. $5 F$ ). Further distal to the zone of B50LI-positive Schwann cell bands, near the maximum outgrowth distance, many fine axonal profiles could be detected with the B-50 antibody (Fig. 5, $G-I$ ). These distal parts of the regenerating axons did not stain with neurofilament antibodies (data not shown).

Control incubations with B-50 antibodies that had been preabsorbed to HPLC-purified B-50 did not show the typical staining of Schwann cell bands and axons distal to the crush in regenerating nerves (Fig. $6 B$ ). The same was true for the staining with the pre-immune serum at equal total $\mathrm{IgG}$ concentrations to the B-50 antibody (Fig. 6C).

The results of EM immunocytochemistry were in accordance with the light-microscopic findings. Proximal to the crush site, some unmyelinated axons contained dense reaction product whereas others did not. Myelinated axons contained very little reaction product (Fig. $7 A$ ). In the proximal part of the regenerated region of nerve, where light immunocytochemistry revealed immunoreactivity associated with bands of Büngner, regenerated axons contained intra-axonal reaction product, but it also outlined Schwann cell and axonal surfaces (Fig. 7, B, C). In more distal regions of regenerated nerve, reaction product was concentrated in axonal profiles, some of which were packed with vesicular material and may be growth cones, with relatively little associated with Schwann cell surfaces (Fig. 7D).

\section{Discussion}

The fast anterograde and retrograde transport of B50LI is in accord with its identity as GAP-43, which is well known as a prominent protein of fast anterograde axonal transport in regenerating nerves (Skene and Willard, 1981a). Retrograde transport of labeled GAP-43 also has been demonstrated (C. Leonard and M. A. Bisby, unpublished observations). However, studies using radioactively labeled GAP-43 give an incomplete picture of the distribution and dynamics of this protein within regenerating nerve. The use of antibodies in the present study shows the existence of the majority (74\%) of the B50LI in the nerve in a static or slowly moving form, and a relatively small amount of retrograde transport of $\mathrm{B} 50 \mathrm{LI}$ in regenerating nerve compared to anterograde transport $(1: 3.2)$. The mean velocity of B50LI transport also is consistent with the fast axonal transport of GAP-43, although the calculated velocity $(5.3 \mathrm{~mm} / \mathrm{hr})$ is less than the velocity of the fastest moving components of fast transport (about $17 \mathrm{~mm} / \mathrm{hr}$ ) (Ochs et al., 1969). However, we cannot conclude that this discrepancy is due to the transport of B50LI in a different type of organelle from that containing the fastestmoving material. The maximum velocities were obtained from the front of a radiolabeled wave, and some material within the wave is traveling more slowly than the front because the wave becomes dispersed as it travels along the axon (Munoz-Martinez et al., 1981). Caution must also be used in interpreting the significance of the small retrograde transport of B50LI. It is possible that the structure of the B-50 molecule is altered prior to its retrograde transport, as happens for some other components of fast transport (e.g., Zarbin et al., 1983), so that it is detected at a lower efficiency by the antibody. Nevertheless, the findings that most of the B50LI within the nerve is stationary, and that there is relatively little retrograde transport of B50LI in regenerating axons, are consistent with the surprising immunocytochemical findings that suggest that B50LI is secreted from regenerated axons.

Localization of B50LI to the newly regenerated nerve segment was anticipated from the finding that a protein concentrated in growth-cone particles (pp46) is identical to GAP-43 (Meiri et al., 1986; Skene et al., 1986). However, it is clear that B50LI is not localized cxclusively to or concentrated within the growthcone region of the axon, because strongly reactive axons could be identified several $\mathrm{mm}$ proximal to the presumed site of the growth cones. The presence of B50LI in other regions of axon suggests that its function is not restricted to some process, such as outgrowth, that is exclusive to the growth cone. 

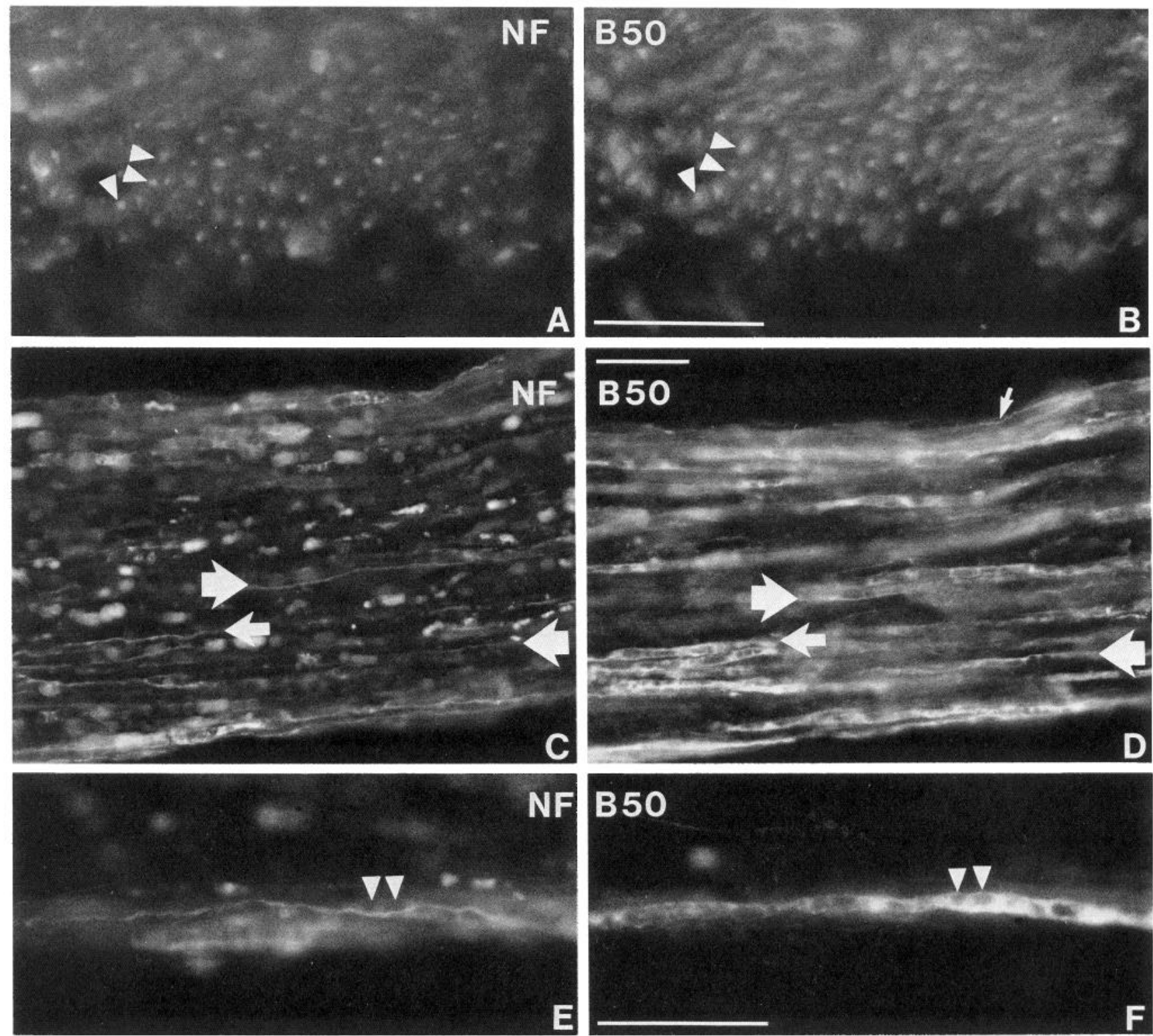

\section{B50}
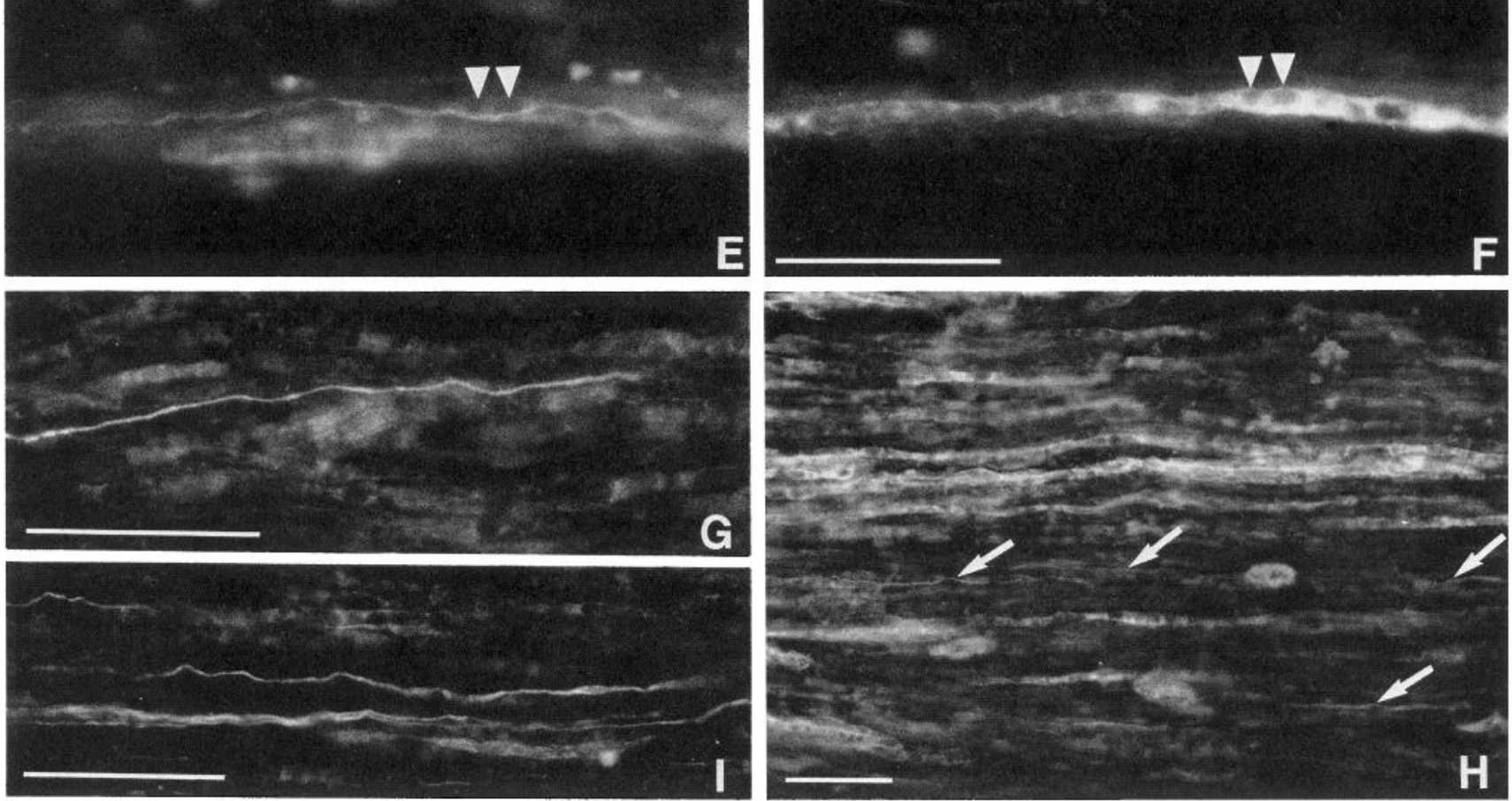

Figure 5. Regenerating rat facial nerve. Double stain for B50LI $(B, D, F)$ and NFI $(A, C, E)$. $A, B$, Cross section of the facial nerve 3 mm proximal to the crush (at $3 \mathrm{~d}$ ), showing discretc B50LI in the axons $(B)$, which do also stain for NFI $(A)$. $C-F$, Regenerating facial nerve $7 \mathrm{~mm}(C, D)$ and $8 \mathrm{~mm}(E, F)$ distal to the crush at $4 \mathrm{~d}$ after lesion. Note the B50LI associated with the Schwann cell bands of Büngner ( $D$, $F$, arrows), which also display NFI axons $(C, E$, arrows). Small arrow in $D$ points out B50LI in a regenerating axon. $G$ and $I$ display B50LI in regenerating axons distal to the zone of B50LI-positive Schwann cells at $8 \mathrm{~mm}, 3 \mathrm{~d} . H$, Transition zone in which these Schwann cell bands become B50LI-negative at 5 $\mathrm{mm}$ distal to the crush, $3 \mathrm{~d}$ after lesion. Arrows indicate several B50LI-positive axons. Scale bars, $100 \mu \mathrm{m}$. 

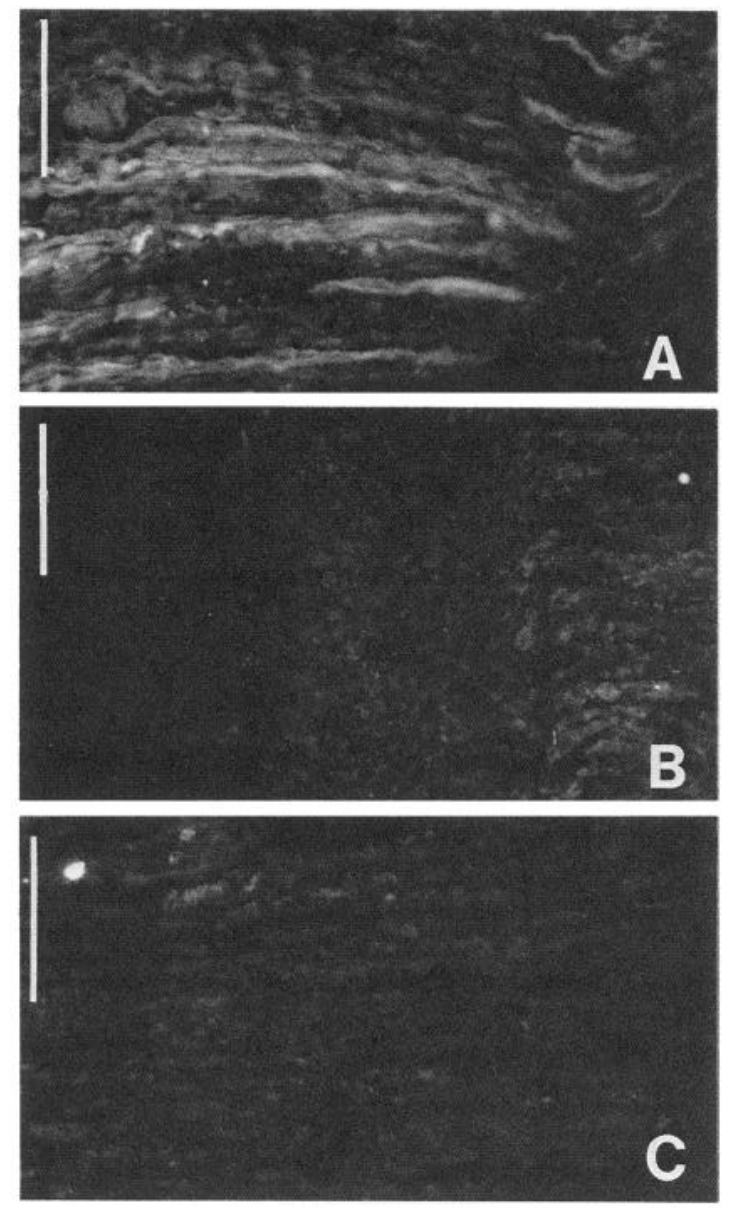

Figure 6. Immunocytochemical controls. Regenerating rat sciatic nerve, distal and adjacent to the crush site, $7 \mathrm{~d}$ after operation. Adjacent sections were stained with B-50 antibody $(A)$ and with this antibody following its absorption to the HPLC-purified B-50 $(B)$. $C$ was stained with pre-immune serum alone at an equivalent IgG concentration (1: 200). None of these controls show the typical staining pattern of Schwann cell bands or axons $(A) . A$ and $B$ were taken at the same photographic and print exposures; the exposure of $C$ is equivalent to Figure $3 F$. Scale bars, $100 \mu \mathrm{m}$.

Although some axons can be found within the regenerating section of sciatic nerve that contains both neurofilament and B50-like immunoreactivity, we were struck by the lack of correspondence (Fig. 4, $E, F$ ). B-50-positive axons lacking neurofilaments are presumably newly regenerated: since axonal elongation rate is greater than neurofilament transport rate, newly regenerated axons would be expected to lack neurofilaments (Tetzlaff and Bisby, 1989). Neurofilament-positive axons lacking distinct B50LI are more difficult to explain because axonal transport of GAP-43 remains elevated in sciatic sensory axons for weeks after the axons have regenerated through this region of nerve close to the crush site (Bisby, 1988). It is possible that different neuronal types represented in sciatic nerve express B- 50 to different extents during regeneration. This is suggested by our observation of intense B50LI associated with small-diameter unmyelinated axons proximal to the injury site (Fig. $4 A-D$ ). However, when B50LI is locally elevated by ligating the nerve, there is good correspondence between B-50 and NFI in the swollen portion of the axons (Fig. 3,E, F). Thus, we suspect that the levels of B50LI in some regenerated axons fall below the threshold for immunocytochemical detection.
The possibility that the extra-axonal localization of B50LI detected in both facial and sciatic nerve is artifactual must be considered, although it is unlikely. First, distal regions containing exclusively intra-axonal B50LI and more proximal regions with intense labeling of bands of Büngner were observed in the same section of nerve: a diffusion artifact occurring during processing would be expected to affect the section uniformly. Second, the zone of extra-axonal labeling was more distal in nerves in which regeneration had proceeded for a longer time, suggesting that this phenomenon represents a time-dependent stage in the maturation of the regenerating nerve. Third, no additional strongly immunoreactive bands were observed on blots of the region of nerve containing extra-axonal labeling compared to regions where labeling was intraneuronal (Fig. 2). Fourth, neither intense intra-axonal nor band-of-Büngner labeling was observed when pre-immune serum was used. Fifth, when B-50 antiserum was preabsorbed to B-50 purified by reverse-phase HPLC, specific staining, both intra- and extra-axonal, was abolished. Sixth, the results of immunocytochemistry at the light and EM levels were complementary.

In general, our results on B50LI localization within the nerve are in agreement with those reported by Verhaagen et al. (1986): Specifically, they reported B50LI in regenerated nerve to be at levels $5 \times$ normal at the crush site and $1.8 \times$ normal proximal to the crush site $6 \mathrm{~d}$ after axotomy. Our corresponding values at $5 \mathrm{~d}$ were $7.2 \times$ and $2.3 \times$. However, these authors did not examine axonal transport.

The extra-axonally located B50LI might be a result of synthesis of B-50 by nerve-sheath cells. This is unlikely, because in preliminary experiments we found no evidence for synthesis of B- 50 by isolated nerve segments in vitro, which is in line with the finding of Basi et al. (1987), who did not detect any GAP43 mRNA in normal or crushed sciatic nerve segments from adult rats. However, Verhaagen et al. (1988) reported a remarkable increase in B50LI at the neuromuscular junction degenerating within $2 \mathrm{~d}$ of denervation, which in sectioned nerves declined thereafter but which in crushed nerves was followed by a second phase of increase presumably due to the arrival of regenerating axons. During the initial (degeneration) phase of B50LI, reaction product was localized between Schwann cells at the neuromuscular junction, but this was not observed during the secondary (reinnervation) phase. Whatever the mechanisms responsible for the extra-axonal B50LI observed at degenerating terminals by Verhaagen et al. (1988), we do not think that our observations were of the same phenomenon. We did not observe extra-axonal reaction product associated with degenerating axons in regions of nerve distal to the growth cones (although we did not examine neuromuscular junctions). Furthermore, we found extra-axonal B50LI in regions of nerve occupied by axons that contained mature regenerated axons: regions containing the growth cones and newly regenerated axons showed very little extra-axonal B50LI. These 2 immunocytochemical reports are at least complementary in showing that B50LI is detectable extraneuronally.

Another possibility for the extra-axonal localization of B50LI that we observed is that it is secreted from axons. Although B-50 behaves as an integral membrane protein (Dosemeci and Rodnight, 1987), the amino-acid sequence of GAP-43/P57/B50 (Basi et al., 1987; Cimler et al., 1987; Karns et al., 1987; Kosik et al., 1988; $\mathrm{Ng}$ et al., 1988; Nielander et al., 1988) does not reveal potential membrane-spanning regions. If B50LI is associated with the inner face of the membrane vectors of fast axonal transport, it could be secreted from the axon by exocy- 

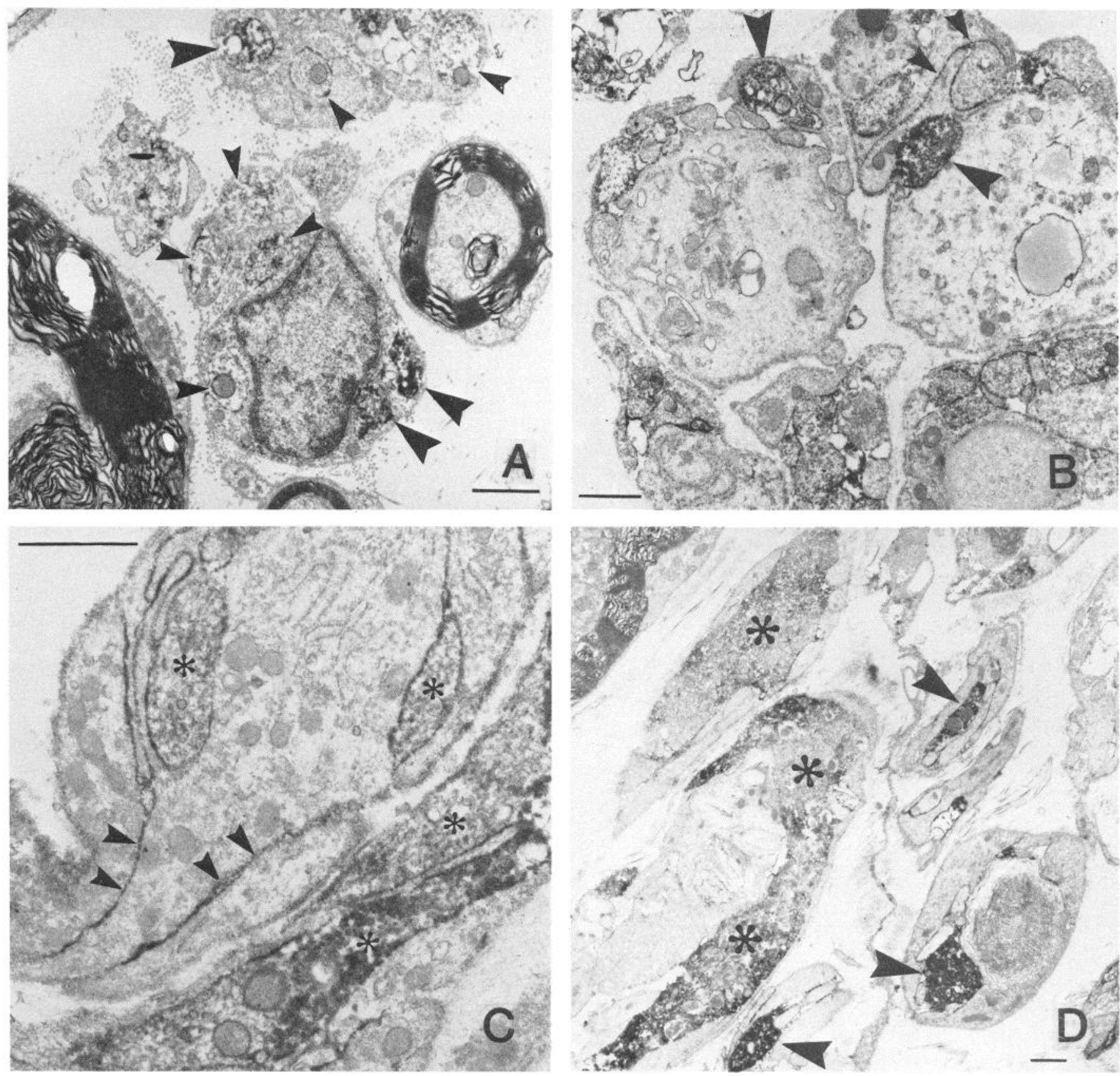

Figure 7. EM immunocytochemistry of rat sciatic nerve, $5 \mathrm{~d}$ after crush lesion. $A, 3 \mathrm{~mm}$ proximal to crush. Dense reaction product is visible within some unmyelinated axons (large arrows) but not others (small arrows). Little or no reaction product is associated with myelinated axons. $B, C, 3 \mathrm{~mm}$ distal to crush. $B$, Reaction product fills some small axons (large arrows) that have regenerated along Schwann cells. Reaction product is also associated with the Schwann cell membranes (small arrows). $C$, At higher magnification, reaction product associated with regenerated axons (asterisks) and Schwann cell membranes (arrows) but not with the Schwann cell cytoplasm. D, $9 \mathrm{~mm}$ distal to crush, dense reaction product in very small axons (arrows) and expanded vesicle-containing structures, which may be growth cones (asterisks). Note less extensive labeling of Schwann cell membranes. Scale bars, $1 \mu \mathrm{m}$.

tosis. Such an exocytosis was reported for at least 5 rapidly transported polypeptides from regenerating bullfrog sciatic nerve (Tedeschi and Wilson, 1987). Unfortunately, the gel system used in those studies probably excluded the frog homologue of GAP43. Similarly, evidence for an axonal secretion of AChE (16Sisoenzyme) from regenerating axons in the facial nerve of guinea pig has been provided in an EM histochemical and biochemical study (Engel et al., 1988). Thus, the release of another fastaxonally-transported protein is not a priori unlikely.

The function of GAP-43/B-50 in axonal regeneration remains unknown. Because there is a correlation between its increased synthesis following injury and its ability to regenerate an axon, and because the relatively specific blockade of synthesis of the frog homolog by tunicamycin (Perrone-Bizzozero and Benowitz, 1987) also inhibits regeneration (Heacock and Agranoff, 1982 ), this protein is thought to be involved critically in axonal elongation. Our finding that B50LI is localized extraneuronally as well as within regenerating axons raises the possibility that GAP-43/B-50 is also involved in axon-Schwann cell interactions that are important to the maturation of regenerating axons. 


\section{References}

Basi, G. S., R. D. Jacobson, I. Virag, J. Schilling, and J. H. P. Skene (1987) Primary structure and transcriptional regulation of GAP43, a protein associated with nerve growth. Cell 49: 785-791.

Benowitz, L. I., and E. R. Lewis (1983) Increased transport of 44,000to 49,000-dalton acidic proteins during regeneration of the goldfish optic nerve: A two-dimensional gel analysis. J. Neurosci. 3: 21532163.

Bisby, M. A. (1978) Fast axonal transport of labelled protein in sensory axons during regeneration. Exp. Neurol. 61: 281-300.

Bisby, M. A. (1982) Ligature techniques. In Axoplasmic Transport, D. G. Weiss, ed., pp. 193-199, Springer-Verlag, Berlin.

Bisby, M. A. (1985) Enhancement of the conditioning lesion effect in rat sciatic motor axons after superimposition of conditioning and test lesions. Exp. Neurol. 90: 385-394.

Bisby, M. A. (1988) Dependence of GAP43 (B50, F1) transport on axonal regeneration in rat dorsal root ganglion neurons. Brain Res. 458: $157-161$.

Bisby, M. A., and P. Keen (1985) Axonal transport of substance P-like immunoreactivity in regenerating rat sciatic nerve. Brain Res. 361: 396-399.

Cimler, B. M., D. H. Giebelhaus, B. T. Wakin, and D. R. Storm (1987) Characterization of murine cDNAS encoding P-57, a neural-specific calmodulin-binding protein. J. Biol. Chem. 262: 12158-12163.

Dosemeci, A., and R. Rodnight (1987) Demonstration by phase-partitioning in Triton X-114 solutions that phosphoprotein B-50 (F1) from rat brain is an integral membrane protein. Neurosci. Lett. 74 : 325-330.

Engel, A. K., W. Tetzlaff, and G. W. Kreutzberg (1988) Axonal transport of $16 \mathrm{~S}$ acetylcholinesterase is increased in regenerating peripheral nerve in guinea pig, but not in rat. Neuroscience 24: 729-738.

Gispen, W. H. (1986) Phosphoprotein B-50 and phosphoinositides in brain synaptic plasma membranes: A possible feed-back relationship. Trans. Biochem. Soc. UK 14: 163-165.

Gutmann E., C. Guttmann, P. B. Medawar, and J. Z. Young (1942) The rate of regeneration of nerve. J. Exp. Biol. 19: 14-44.

Heacock, A. M., and B. W. Agranoff (1982) Protein synthesis and transport in the regenerating goldfish visual system. Neurochem. Res. 7: $771-788$.

Hoffman, P. N., G. W. Thompson, J. W. Griffin, and D. L. Price (1985) Changes in neurofilament transport coincide temporally with alterations in the caliber of axons in regenerating motor fibers. J. Cell Biol. 101: $1332-1340$.

Hoffman, P. N., D. W. Cleveland, J. W. Griffin, P. W. Landes, N. J. Cowan, and D. L. Price (1987) Neurofilament gene expression: A major determinant of axonal caliber. Proc. Natl. Acad. Sci. USA 84: $3472-3476$

Kalil, K., and J. H. P. Skene (1986) Elevated synthesis of an axonally transported protein correlates with axon outgrowth in normal and injured pyramidal tracts. J. Neurosci. 6: 2563-2570.

Karns, L. R., S. C. Ng, J. A. Freeman, and M. C. Fishman (1987) Cloning of complementary DNA for GAP-43, a neuronal growthrelated protein. Science 236:597-600.

Kosik, K. S., L. D. Orecchio, G. A. P. Bruns, L. I. Benowitz, G. P. MacDonald, D. R. Cox, and R. L. Neve (1988) Human GAP43: Its deduced amino acid sequence and chromosomal localization in mouse and human. Neuron 1: 127-132.

Lovinger, D. M., R. F. Akers, R. B. Nelson, C. A. Barnes, B. L. McNaughton, and A. Routtenberg (1985) A selective increase in phosphorylation of protein $F 1$, a protein kinase $C$ substrate, directly related to three day growth of long term synaptic enhancement. Brain Res. 343: 137-145.

Lowry, O. H., N. J. Rosebrough, A. L. Farr, and R. J. Randall (1951) Protein measurement with the Folin phenol reagent. J. Biol. Chem. 193: 265-275.

McLean, I. W., and P. K. Nakane (1974) Periodate-lysine-paraformaldehyde fixative for immuno-clectron microscopy. J. Histochem. Cytochem. 22: 1077-1083.

McMaster, D., H. Zwiers, and K. Lederis (1988) The growth-associated, neuronal tissue specific, Kinase $C$ substrate protein B-50: Improved purification procedure and partial aminoacid sequence. Brain Res. Bull. 21: 265-276.

Meiri, K. F., K. H. Pfenninger, and M. B. Willard (1986) Growth- associated protein, GAP-43, a polypeptide that is induced when neurons extend axons, is a component of growth cones and corresponds to pp46, a major polypeptide of a subcellular fraction enriched in growth cones. Proc. Natl. Acad. Sci. USA 83: 3537-3541.

Munoz-Martinez, E. J., R. Nunez, and A. Sanderson (1981) Axonal transport: A quantitative study of retained and transported protein fraction in the cat. J. Neurobiol. 12: 15-26.

Ng, S. C., S. M. de la Mante, G. L. Conboy, L. R. Karns, and M. C. Fishman (1988) Cloning of human GAP43: Growth association and ischemic resurgence. Neuron 1: 133-139.

Nielander, H. B., L. H. Schrama, A. J. van Rozen, M. Kasperaitis, A. B. Oestreicher, P. N. E. de Graan, W. Gispen, and P. Schotman (1988) Primary structure of the neuron-specific phosphoprotein B-50 is identical to growth-associated protein GAP-43. Neurosci. Res. Commun. 1: 163-172.

Ochs, S., M. I. Sabri, and J. Johnson (1969) Fast transport system of materials in mammalian nerve fibres. Science 163: 686-687.

Oestreicher, A. B., C. J. Van Dongen, H. Zwiers, and W. H. Gispen (1983) Affinity-purified anti B-50 protein antibody: Interference with the function of the phosphoprotein B-50 in synaptic plasma membranes. J. Neurochem. 41: 331-340.

Perrone-Bizzozero, N. I., and L. I. Benowitz (1987) Expression of a 48-kilodalton growth-associated protein in the goldfish retina. J. Neurochem. 48: 644-652.

Redshaw, J. D., and M. A. Bisby (1987) Proteins of fast axonal transport in regenerating rat sciatic sensory axons: A conditioning lesion does not amplify the characteristic response to axotomy. Exp. Neurol. 98: 212-221.

Reh, T. A., J. D. Redshaw, and M. A. Bisby (1987) Axons of the pyramidal tract do not increase their transport of growth-associated proteins after axotomy. Mol. Brain Res. 2: 1-6.

Skene, J. H. P. (1984) Growth-associated proteins and the curious dichotomies of nerve regeneration. Cell 37: 697-700.

Skene, J. H. P., and M. Willard (1981a) Changes in axonally transported proteins during axon regeneration in toad retinal ganglion cells. J. Cell Biol. 89: 86-95.

Skene, J. H. P., and M. Willard (1981b) Axonally transported proteins associated with axon growth in rabbit central and peripheral nervous system. J. Cell Biol. 89: 96-103.

Skene, J. H. P., R. D. Jacobson, G. J. Snipes, C. B. McGuire, J. J. Norden, and J. A. Freeman (1986) A protein induced during nerve growth (GAP-43) is a major component of growth-cone membranes. Science 233: 783-785.

Tedeschi, B., and D. L. Wilson (1987) Subsets of axonally transported and periaxonal polypeptides are released from regenerating nerve. $J$ Neurochem. 48: 463-469.

Tetzlaff, W., and M. A. Bisby (1989) Neurofilament elongation into regenerating facial nerve axons. Neuroscience (in press).

Tetzlaff, W., M. A. Bisby, and G. W. Kreutzberg (1988) Changes in cytoskeletal proteins in the rat facial nucleus following axotomy. $\mathrm{J}$. Neurosci. 8: 3181-3189.

Verhaagen, J., C. O. M. Van Hooff, P. M. Edwards, P. N. E. De Graan A. B. Oestreicher, P. Schotman, F. G. I. Jennekens, and W. H. Gispen (1986) The kinase $C$ substrate protein $\mathrm{B}-50$ and axonal regeneration. Brain Res. Bull. 17: 737-741.

Verhaagen, J., A. B. Oestreicher, P. M. Edwards, H. Veldman, F. G. I. Jennekens, and W. H. Gispen (1988) Light- and electron-microscopical study of phosphoprotein B-50 following denervation and reinnervation of the rat soleus muscle. J. Neurosci. 8: 1759-1766.

Zarbin, M. A., J. M. Palacios, J. K. Wamsley, and M. J. Kuhar (1983) Axonal transport of Beta-adrenergic receptors. Antero- and retrogradely transported receptors differ in agonist affinity and nucleotide sensitivity. Mol. Pharmacol. 24: 341-348.

Zwiers, H., J. Verhaagen, C. J. Van Dongen, P. N. E. De Graan, and W. H. Gispen (1985) Resolution of rat brain synaptic phosphoprotein B-50 into multiple forms by two-dimensional electrophoresis: Evidence for multisite phosphorylation. J. Neurochem. 44: 10831090.

Zwiers, H., A. B. Oestreicher, M. A. Bisby, P. N. E. De Graan, and W. H. Gispen (1987) Protein kinase C substrate B50 in adult and developing rat brain is identical to axonally-transported GAP43 in regenerating peripheral rat nerve. In Axonal Transport, R. S. Smith and M. A. Bisby, eds., pp. 421-433, Liss, New York. 